\title{
LITERATURA E LIVRO DIDÁTICO NO BRASIL: A EXCLUSÃO DA LITERATURA DE AUTORIA INDÍGENA NO ENSINO MÉDIO
}

\author{
LITERATURE AND DIDACTIC BOOK IN BRAZIL: THE EXCLUSION OF \\ INDIGENOUS AUTHORITY LITERATURE IN HIGH SCHOOL
}

\author{
LITERATURA Y LIBRO DIDÁCTICO EN BRASIL: LA EXCLUSIÓN DE LA \\ LITERATURA DE AUTORÍA INDÍGENA EN LA ENSEÑANZA MEDIO
}

\author{
Adriana Folle ${ }^{1}$, Luana Teixeira Porto ${ }^{2}$
}

\begin{abstract}
RESUMO
Este artigo aborda a memória sócio-histórica e cultural construída por meio da leitura da literatura, destacando esta arte é uma das formas de expressão cultural que singularizam a história de um povo e de uma nação. Ao tratar desse tema, o estudo discute a contribuição da literatura de autoria indígena como elemento crucial para a memória social, histórica e cultural do Brasil. O objetivo do trabalho é refletir sobre o ensino de literatura no Ensino Médio e a construção de uma memória sobre a cultura, a sociedade e a história brasileira por meio da leitura de literaturas representativas dos povos brasileiros, apontando a ausência sistemática das produções literárias indígenas em materiais didáticos de literatura brasileira. Para desenvolver o estudo, são adotados como referencial teórico o conceito de memória sócio-histórica e perspectivas críticas sobre o ensino de literatura no Brasil e sobre a cultura indígena como tema obrigatório no ensino básico brasileiro. Para a abordagem proposta, elegem-se como objeto de análise livros didáticos de Língua Portuguesa e literatura adotados no Ensino Médio em escolas públicas brasileiras e disponibilizados pelo Programa Nacional do Livros Didático (PNLD). Ao discutir a produção literária brasileira pelo viés da historiografia, como propõem a maioria dos livros didáticos, nota-se um apagamento da autoria indígena nos materiais pedagógicos, o que compromete não só a construção de uma memória social e cultural das letras brasileiras.
\end{abstract}

PALAVRAS-CHAVE: Ensino de literatura. Literatura indígena. Livro didático. Ensino médio.

\section{ABSTRACT}

This article approaches the socio-historical and cultural memory built through the reading of literature, highlighting this art is one of the forms of cultural expression that singles out the history of a people and a nation. In addressing this theme, the study discusses the contribution of indigenous authorship literature as a crucial element for the social, historical and cultural memory of Brazil. The objective of this work is to reflect on the teaching of literature in High School and the construction of a memory about Brazilian culture, society and history through the reading of literatures representative of the Brazilian peoples,

\footnotetext{
${ }^{1}$ Jornalista e Mestre em Letras - URI.

${ }^{2}$ Doutora em Letras e Professora do Programa de Pós-graduação em Educação - Mestrado em Letras da URI.
}

\begin{tabular}{l|l} 
Recebido em: 04/10/2018 & Aceito em: 30/10/2018
\end{tabular}




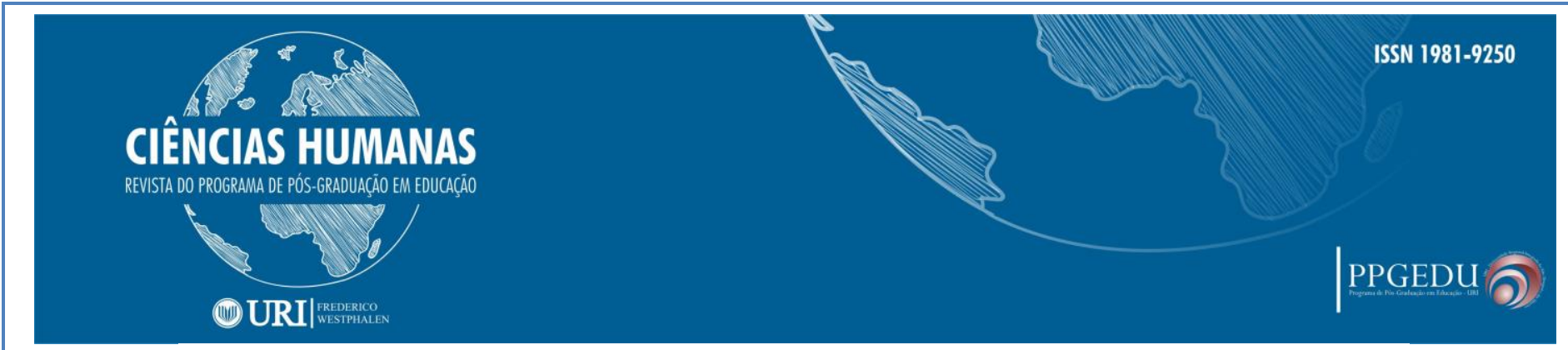

pointing to the systematic absence of indigenous literary productions in materials of Brazilian literature. To develop the study, the concept of socio-historical memory and critical perspectives on the teaching of literature in Brazil and on indigenous culture as a mandatory subject in Brazilian basic education are adopted as theoretical reference. For the proposed approach, textbooks of Portuguese Language and literature adopted in High School in Brazilian public schools and made available by the National Program of Didactic Books (PNLD) are chosen as the object of analysis. In discussing Brazilian literary production through the bias of historiography, as most textbooks propose, we can see a deletion of indigenous authorship in pedagogical materials, which compromises not only the construction of a social and cultural memory of Brazilian letters.

KEYWORDS: Literature teaching. Indigenous literature. Textbook. High school.

\section{RESUMEN}

Este artículo aborda la memoria sociocultural y cultural construida a través de la lectura de la literatura, destacando este arte es una de las formas de expresión cultural que singularizan la historia de un pueblo y de una nación. Al tratar este tema, el estudio discute la contribución de la literatura de autoría indígena como elemento crucial para la memoria social, histórica y cultural de Brasil. El objetivo del trabajo es reflexionar sobre la enseñanza de literatura en la Enseñanza Media y la construcción de una memoria sobre la cultura, la sociedad y la historia brasileña por medio de la lectura de literaturas representativas de los pueblos brasileños, apuntando la ausencia sistemática de las producciones literarias indígenas en materiales didácticos de literatura brasileña. Para desarrollar el estudio, se adoptan como referencial teórico el concepto de memoria socio-histórica y perspectivas críticas sobre la enseñanza de literatura en Brasil y sobre la cultura indígena como tema obligatorio en la enseñanza básica brasileña. Para el enfoque propuesto, son elegidos como los libros de texto objeto de análisis de la lengua portuguesa y de la literatura en Educación Secundaria en las escuelas públicas brasileñas y puestos a disposición por el Programa Nacional de Libros didácticos (NPDB). Al discutir la producción literaria brasileña por el sesgo de la historiografía, como proponen la mayoría de los libros didácticos, se nota un borrado de la autoría indígena en los materiales pedagógicos, lo que compromete no sólo la construcción de una memoria social y cultural de las letras brasileñas.

PALABRAS CLAVE: Enseñanza de literatura. Literatura indígena. Libro didáctico. Enseñanza media.

\section{CONSIDERAÇÕES INICIAIS}

A história de uma nação é registrada por seu povo, suas produções culturais, documentos e construções arquitetônicas, entre outros elementos, que formam, juntos, um patrimônio material e imaterial que permite (re)contar comportamentos, cotidianos, experiências e reproduzir vivências de comunidades em diferentes tempos e espaços. No caso brasileiro, nossa história como nação remonta a nossos ancestrais, a indígenas que habitavam essa terra tropical antes da chegada dos colonizadores europeus e que mantinham hábitos e costumes que singularizaram o início do processo de colonização no país e que foram registrados em desenhos, construções, peças artesanais, enfim, em instrumentos que constituem um patrimônio material. Já o patrimônio imaterial dos povos indígenas, que pode ser apreendido pelas produções literárias, por exemplo, nem

\begin{tabular}{l|c|c|c|}
\hline Rev. Ciências Humanas & Frederico Westphalen, RS & Pg. 05 - 23 & mai./ago. 2018
\end{tabular}

\begin{tabular}{l|l} 
Recebido em: 04/10/2018 & Aceito em: 30/10/2018
\end{tabular}




\section{CIÊNCIAS HUMANAS}

REVISTA DO PROGRAMA DE PÓS-GRADUAĞ̈O EM EDUCAĞ̄o

\section{(1) URI|}

sempre recebeu adequada atenção e registro para que a memória sobre essa arte da palavra pudesse transitar em outros contextos sociais, históricos e culturais.

A literatura de autoria indígena, apesar de figurar como um dos tópicos que fazem parte da cultura indígena, que, por força de lei $^{3}$, deve ser ensinada na escola e apesar de ser reconhecida como expoente fundamental da cultura brasileira e das tribos que ainda permanecem vivas em nosso território, não é tema frequente de aulas de literatura na Educação Básica nem no Ensino Médio. E essa escassez de abordagem provoca, dentre outras situações, o risco de apagamento da cultura indígena expressa por manifestações literárias no imaginário tanto de indígenas quanto de não indígenas no Brasil e, consequentemente, lacunas na memória sócio-histórica e cultural construída por meio da leitura da literatura no Brasil e de sua relação com os povos que formam a pluralidade étnica e cultural do país.

Considerando isso e a importância do resgate das origens do povo brasileiro, no qual se destacam os indígenas como primordiais na construção cultural e identitária do nosso país, idealizamos este artigo, que discute a contribuição da literatura de autoria indígena como elemento crucial para a memória social, histórica e cultural do Brasil e defende a necessidade de leitura e estudo das produções literárias indígenas na sala de aula, especialmente no nível básico de ensino brasileiro. O objetivo do trabalho é refletir sobre o ensino de literatura no Ensino Médio e a construção de uma memória sobre a cultura, a sociedade e a história brasileira por meio da leitura de literaturas representativas dos povos brasileiros, apontando a ausência sistemática das produções literárias indígenas em materiais didáticos de literatura brasileira.

Para desenvolver o estudo, são adotados como referencial teórico estudos sobre literatura de autoria indígena e sobre o conceito de memória sócio-histórica, além de apontamentos sobre o ensino de literatura no Brasil e sobre a cultura indígena como tema obrigatório no ensino básico brasileiro. Para a abordagem proposta, elegem-se

\footnotetext{
${ }^{3}$ Há, no Brasil, leis - 10.639/2003 e 11.645/2008 (Diretrizes Curriculares Nacionais para a Educação das Relações Étnico-Raciais e para o Ensino de História e Cultura Afro-Brasileira, Africana e Indígena) que, através do Instituto Nacional de Estudos e Pesquisas Educacionais Anísio Teixeira (INEP), impõem a discussão e o ensino da cultura indígena e também obrigam a inclusão de conteúdos em disciplinas e em atividades curriculares da Educação das Relações Étnico-Raciais.
} 


\section{CIÊNCIAS HUMANAS}

REVISTA DO PROGRAMA DE PÓS-GRADUAĞ̈O EM EDUCAĞ̄o

\section{(1) URI|}

como objeto de análise livros didáticos de Língua Portuguesa e literatura adotados no Ensino Médio em escolas públicas brasileiras e disponibilizados pelo Programa Nacional do Livros Didático (PNLD).

\section{A literatura indígena}

A literatura indígena brasileira não figura entre obras canônicas e vemos que essa produção literária envolve uma minoria étnica pouco valorizada nos ambientes de formação escolar. $\mathrm{Na}$ definição corrente, cânone literário significa um conjunto de obras-primas, que devem ser estudadas e preservadas como patrimônio da humanidade, por serem consideradas paradigmas universais e atemporais: os clássicos. Porém, a literatura indígena não é uma obra considerada modelo apesar de a tradição de estes nativos fazer parte do patrimônio cultural brasileiro.

Para além da exclusão da literatura indígena no contexto literário canônico brasileiro e em uma tentativa de compreender essa indiferença, basta discutir a forma como o indígena é apresentado pelo não indígena. Para Daniel Munduruku (2009, p. 2024), a imagem de "selvagem" e de incapaz atribuída aos grupos indígenas diz respeito justamente a uma construção etnocêntrica e unilateral da alteridade e essa mediação é balizada em uma visão de mundo que toma como unicamente válidos os seus próprios pressupostos, relegando aos indígenas uma imagem de um outro destituído de história, de escrita, estático em um passado em que foi adicionado mediante sua relação com o colonizador.

Independentemente do cânone, é preciso discutir a especificidade da literatura indígena, para desenvolver uma reflexão sobre sua importância no contexto da cultura brasileira. Antes de existirem escritores indígenas - que têm a capacidade de contar as suas histórias como elas realmente aconteceram, já que passaram suas vidas junto a esta cultura, aprendendo e ensinando -, toda contribuição cultural indígena era coletada, selecionada, modificada e registrada pelos "brancos". De acordo com Érika Bergamasco Guesse (2011), certamente, essa intermediação fazia com que muito da originalidade das narrativas fosse perdida: 


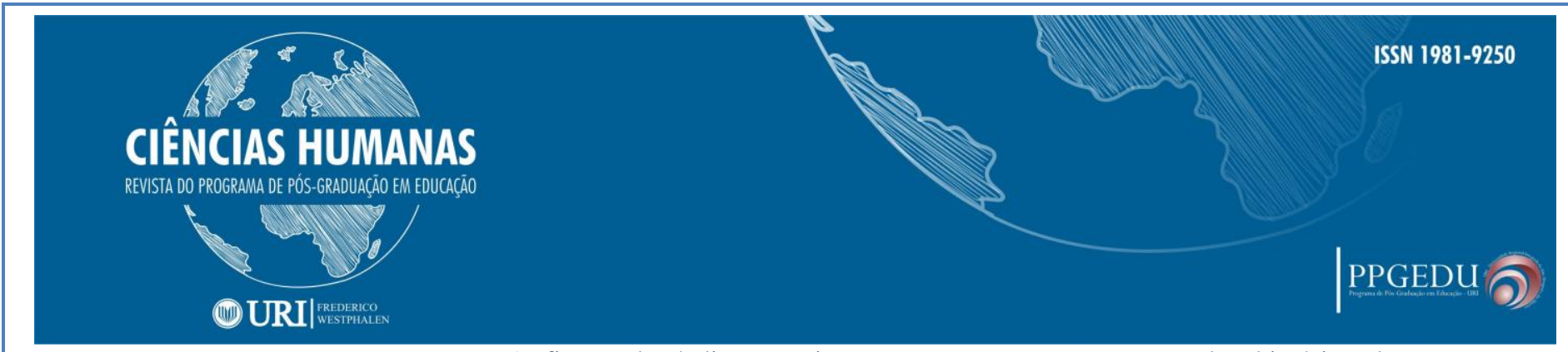

A figura do índio era vista apenas como personagem das histórias dos brancos ou os brancos se posicionavam como "donos"/autores das histórias dos índios. O que tem acontecido nas últimas décadas é que os próprios indígenas têm assumido a voz narrativa, tornando-se sujeitos, autores/ criadores de seu legado cultural escrito que, por sua vez, é a expressão de seu legado mítico e mágico. Uma característica significativa dos livros de literatura indígena é o diálogo entre os textos escritos e visuais; a grande maioria das narrativas é acompanhada de desenhos bem coloridos, feitos pelos próprios índios. Para os indígenas, as ilustrações têm a mesma importância das histórias escritas e, em alguns casos, possuem um significado cultural. Há ainda algumas comunidades que consideram o texto escrito como uma complementação ou "ilustração" do texto visual, segundo Souza (2006). Em alguns casos, os editores não-índios, ao configurarem os textos indígenas, desconhecem o valor do elemento visual, e dão, erroneamente, maior importância ao texto verbal alfabético (GUESSE, 2011, p. 2).

Já Graça Graúna (2013) frisa que, gerando a sua própria teoria, a literatura escrita dos povos indígenas no Brasil pede que se leiam as várias faces de sua transversalidade, a começar pela estreita relação que mantém com a literatura de tradição oral, com a história de outras nações excluídas (as nações africanas, por exemplo), com a mescla cultural e outros aspectos fronteiriços que se manifestam na literatura estrangeira e, acentuadamente, no cenário da literatura nacional. Mesmo com este agrupamento de diferentes culturas, Graúna assegura que há escassez de estudos em torno do assunto indígena como decorrência do preconceito: "Daí a falta de reconhecimento da existência dessa literatura (seja ela contemporânea ou não)" (GRAÚNA, 2013, p. 19-20).

É do conhecimento da população, de modo geral, que a cultura indígena foi sendo apagada pelo povo europeu. Possivelmente por falta de informação, as pessoas não conhecem e também não se interessam em aprender sobre esta cultura, não dão importância sobre o patrimônio cultural que deixa de ser valorizado. Talvez por este motivo, de acordo com Graúna (2013), a literatura brasileira tem se revelado mais excludente do que se caracterizado pela convivência solidária na abordagem de temas relacionados ao índio, ao negro, ao judeu, à mulher, à criança, ao homossexual e ao idoso, entre outros segmentos que a sociedade dominante rotula de minorias. Nas palavras da pesquisadora, "passando o olhar pela geografia dos excluídos, por exemplo, as minorias são os milhões de desempregados, maiores e menores abandonados semteto, sem-terra, sem vez, sem voz, espalhados pelo país" (GRAÚNA, 2013, p. 44). 


\section{CIÊNCIAS HUMANAS}

REVISTA DO PROGRAMA DE PÓS-GRADUAĞ̈O EM EDUCAĞ̄o

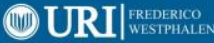

As últimas décadas do século $\mathrm{XX}$ foram determinantes para a conquista de direitos das sociedades indígenas. Isso pode ser confirmado por Iara Tatiana Bonin (2015), que diz que "foi a partir da segunda metade do século XX que a literatura indígena adquiriu notoriedade". A partir dos anos 1990, de acordo com Bonin (2015), talvez o nome mais expressivo na literatura indígena seja o de Daniel Munduruku, que lançou seu primeiro livro, Histórias de Índio, pela Companhia das Letrinhas, em 1996:

Juntamente com ele, surgem outros escritores: Yaguarê Yamã, Olívio Jekupé, Kaká Werá Jekupé, René Kithãulu, Wasiry Guará. Aos poucos, algumas obras de autoria indígena têm sido incorporadas às listagens do Programa Nacional Biblioteca na Escola (PNBE), permitindo a ampla circulação dessas textualidades nas escolas públicas de todo o país (BONIN, 2015, p. 24).

Ainda, segundo Bonin (2015), embora existam registros de escritos indígenas desde o século XVIII, a expressão literatura indígena tem sido assumida mais recentemente para designar as textualidades produzidas por integrantes de diferentes povos. Por isso, é importante esclarecer nomenclaturas da produção literária que aborda a temática indígena e que recebe uma divisão relacionada à autoria: a literatura indígena é a escrita por nativos, por autores indígenas; e a literatura indianista é a que possui obras que abordam à temática indígena por autores não-indígenas, tendo como exemplo o texto da Carta, de Caminha. Graúna (2013, p. 21) traz os conceitos de indianismo, que se referem à literatura de temática indígena escrita por autores(as) não-indígenas, e o indianismo literário escrito por autores(as) com esta descendência, como é o caso de Olívio Jekupé, que, por ser índio, consegue detalhar a vida deste povo, com muita propriedade, em suas obras.

Explicada a diferença entre literatura indígena e indianista, usadas na forma escrita, também necessário ater-se sobre como é vista a produção baseada na oralidade. Janice Thiél (2006, p.196) diz que estabelecer como literários os textos fixados pela escrita significa classificar como não-literários os textos da produção oral, que podem ser atualizados e alterados a cada enunciação. Para a pesquisadora, "Assim, parece ser criado um distanciamento entre a construção discursiva que conduz à literatura e aquela que compõe a oratura. [...] Ademais, as noções de autoria, público e tradição, 


\section{CIÊNCIAS HUMANAS}

REVISTA DO PROGRAMA DE PÓS-GRADUAĞ̈O EM EDUCAĞ̄o

\section{(1) URI|}

necessárias à constituição de um sistema literário, segundo Mello e Souza, assumem características próprias na criação textual indígena” (THIÉL, 2006, p. 196).

Há também, no contexto da literatura indígena, as narrativas multimodais. Quem tem acesso a obras indígenas sabe que a maioria delas trabalha com a apresentação de imagens e texto. Boa parte das narrativas é acompanhada de desenhos bem coloridos, feitos pelos próprios índios. Para os indígenas, as ilustrações têm a mesma importância das histórias escritas e, em alguns casos, possuem também um significado cultural, já que detalham imagens que representam a vida, os usos e costumes destes nativos. Há ainda algumas comunidades que consideram o texto escrito como uma complementação ou "ilustração" do texto visual, segundo Lynn Mario T. Menezes de Souza (2006). Porém, há editores de livros não-indígenas que desconsideram as ilustrações, não dando o verdadeiro valor ao elemento visual que ilustra uma página e na maioria das vezes ajuda as pessoas a melhor entenderem o texto escrito. Souza denomina essas narrativas indígenas de narrativas multimodais, a partir do conceito de Kress e van Leeuwen, que "definem a multimodalidade da linguagem como o uso justaposto e simultâneo de linguagens verbais e não verbais, como, por exemplo, o uso, num mesmo texto, de linguagem verbal alfabética ao lado de uma imagem fotográfica, não-verbal" (SOUZA apud GUESSE, 2014).

As produções literárias indígenas têm autorias individuais e coletivas. Conforme Guesse (2013, p. 2), os objetivos primeiros das publicações de autoria indígena - mais frequentemente subsidiadas por órgãos oficiais ou por organizações não governamentais, quando se trata de autoria coletiva, e/ ou publicadas por editoras privadas, geralmente quando se trata de autoria individual - seriam atender à demanda escolar indígena, auxiliando os professores no ensino da escrita e leitura nas escolas das aldeias, e informar os brasileiros sobre a existência desses povos, constituindo-se, dessa forma, como um movimento político-literário.

\section{A memória sócio-histórica: perspectiva teórica}




\title{
CIÊNCIAS HUMANAS
}

REVISTA DO PROGRAMA DE PÓS-GRADUAĞ̈O EM EDUCAĞ̄o

\section{(1) URI|}

A memória social e cultural é importante para qualquer cultura e não podia ser diferente para os indígenas. A transmissão da tradição, baseada nas lembranças e aprendizados passados, guardados na memória individual e coletiva - através de experiências compartilhadas -, é a base para dar continuidade à cultura local de cada tribo. Esta cultura é uma construção social, produzida pelas pessoas a partir de suas relações, de suas experiências vividas e de seus valores. A memória sofre transformações à medida que o tempo passa. Com isso, é possível afirmar que a memória não é apenas um registro histórico dos fatos, mas uma combinação de ações sociais passadas, com fatores importantes da vida social do presente, assim sendo permanentemente reconstruída.

O pesquisador Jan Assmann (apud DOURADO, 2013) faz uma distinção entre dois tipos de memória: a comunicativa, relacionada à transmissão difusa de lembranças no cotidiano, através da oralidade; e a memória cultural, referente a lembranças objetivadas e institucionalizadas, que podem ser armazenadas, repassadas e reincorporadas ao longo das gerações. Para o autor,

\begin{abstract}
A memória cultural é constituída, assim, por heranças simbólicas materializadas em textos, ritos, monumentos, celebrações, objetos, escrituras sagradas e outros suportes mnemônicos que funcionam como gatilhos para acionar significados associados ao que passou. Além disso, remonta ao tempo mítico das origens, cristaliza experiências coletivas do passado e pode perdurar por milênios. Por isso, pressupõe um conhecimento restrito aos iniciados (ASSMANN apud DOURADO, 2013. s.p).
\end{abstract}

O pesquisador ainda cita a memória comunicativa, dizendo que ela se restringe ao passado recente, evoca lembranças pessoais e autobiográficas e é marcada pela durabilidade de curto prazo, de 80 a 110 anos, de três a quatro gerações. De modo geral, a memória é o processo de adquirir, armazenar e recuperar informações que foram assimiladas pela mente. Seguindo esse princípio, ainda há outro tipo de memória, a social, que seria a coletivização desse processo. $\mathrm{O}$ escritor que deu origem a esse pensamento foi o sociólogo Maurice Halbwachs (1968, traduzido por BENOIR, 2004). Ele afirma que memória social é a essência do conhecimento coletivo e culturalmente conhecido por determinado grupo balizado por um determinado contexto. 


\section{CIÊNCIAS HUMANAS}

REVISTA DO PROGRAMA DE PÓS-GRADUAĞ̈O EM EDUCAĞ̄o

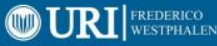

Outro autor também conceitua memória social e faz a aproximação com o pensamento de identidade. Michael Pollak (1992) afirma que, em todos os níveis, a memória é um fenômeno construído social e individualmente e que quando se trata da memória herdada, podemos também dizer que há uma ligação fenomenológica muito estreita entre a memória e o sentimento de identidade.

Apesar de alguns autores expressarem como entendem a memória social, são inúmeras as dificuldades quando se tenta conceituá-la. Campos abertos, assim como “cultura", possibilitam várias discussões já que não possuem regras claras nem fórmulas lógicas, certas. Por este motivo, é difícil chegar a um conceito satisfatório. A psicanalista Jô Gondar (2005) ressalta isso com a afirmação: “dois perigos, entretanto, costumam ameaçar os territórios abertos e colhedores do múltiplo: a ausência de rigor e o ecletismo ético". Para não se comprometer com estas dificuldades, a autora não tenta conceituar, mas elabora quatro proposições sobre memória social. A primeira delas: o conceito de memória social é transdisciplinar:

A memória social, como objeto de pesquisa passível de ser conceituado, não pertence a nenhuma disciplina tradicionalmente existente, e nenhuma delas goza do privilégio de produzir o seu conceito. Esse conceito se encontra em construção a partir de novos problemas que resultam do atravessamento de disciplinas diversas. (GONDAR, 2005).

A escritora esclarece também que o conceito de "memória social" não pode ser multidisciplinar, já que para a uma boa compreensão não bastaria apenas somar saberes de duas ou mais disciplinas. A memória social também não se bastaria sendo interdisciplinar, porque a intersecção de saberes de mais de uma disciplina não seria suficiente para essa definição. Em ambos os casos, ainda haveria algo sem explicação. Os estudos nesta área não têm o intuito de relativizar as diferenças e sugerir uma interação harmoniosa, mas sim interrogar a memória social a partir de sua natural transversalidade.

Em seguida, a estudiosa apresenta a segunda proposição: o conceito de memória social é ético e político: 


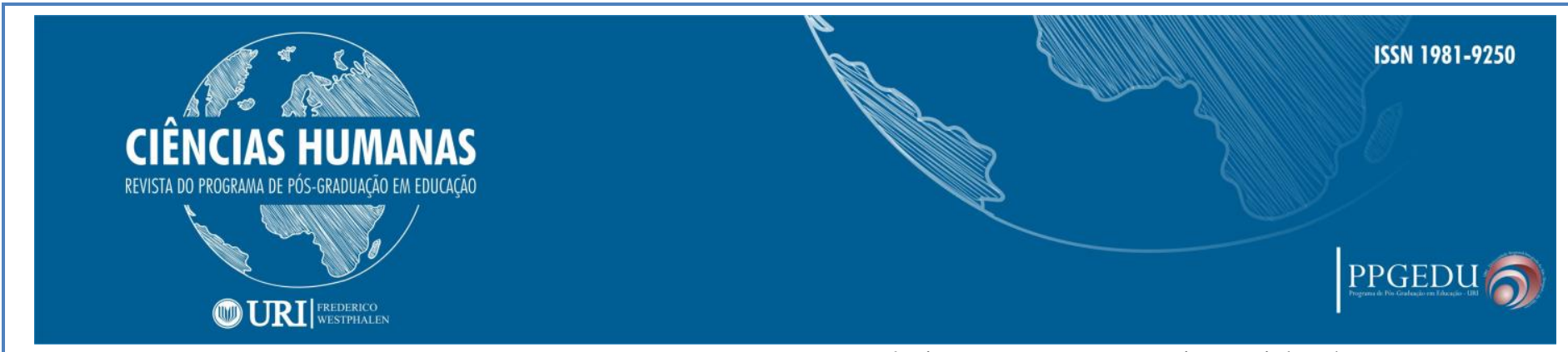

Uma apresentação panorâmica e pretensamente imparcial sobre as diversas noções de memória social pode parecer aberta às diferenças, mas de fato encobre uma pretensão totalizante em que as diferenças se esvaem, pois se o conceito de memória social apresenta significações diferentes, isso não quer dizer que elas sejam equivalentes. (GONDAR, 2005).

Com esta afirmação, a autora diz que a história é sempre parcial, sendo contada por um determinado grupo ou classe, geralmente uma classe dominante. Segundo ela, na história contada, são sempre impressas percepções que não são pura verdade, elevando a importância de alguns fatos e relevando outros acontecimentos.

Após, é descrita a terceira proposição: a memória é uma construção processual:

\begin{abstract}
A memória não nos conduz a reconstituir o passado, mas sim a reconstruí-lo com base nas questões que nós fazemos, que fazemos a ele, questões que dizem mais de nós mesmos, de nossa perspectiva presente, que do frescor dos acontecimentos passados (GONDAR, 2005).
\end{abstract}

Desta maneira, a estudiosa diz que a memória é construída e reconstruída por cada um cada vez que ela é contada. Por este motivo, das quatro proposições, essa talvez seja a que gera maior controvérsia, pois a autora admite que a memória é uma construção e ataca a ideia de que a memória é sinônimo de representação coletiva.

Para finalizar, é abordada a quarta proposição: a memória não se reduz à representação. "Se reduzirmos a memória a um campo de representações, desprezamos as condições processuais de sua produção" (GONDAR, 2005). Assim, ela detalha que a memória é algo muito maior do que as meras representações. A metáfora do iceberg se encaixa nesse conceito. Desta forma, a representação seria somente a ponta do iceberg, sendo que a memória em si seria toda a parte que não é visível, que está escondida, mas que dá toda a sustentação da representação.

Levando em consideração as quatro proposições da autora, é possível perceber que Gondar demonstra uma linha de pensamento que é contrária aos processos de resgate da memória. Ela deixa claro que a memória não pode ser simplesmente resgatada, sempre haverá mudanças. Considerando que há mudanças, torna-se muito mais simples admitir que a memória é uma construção e que se modificará constantemente. 


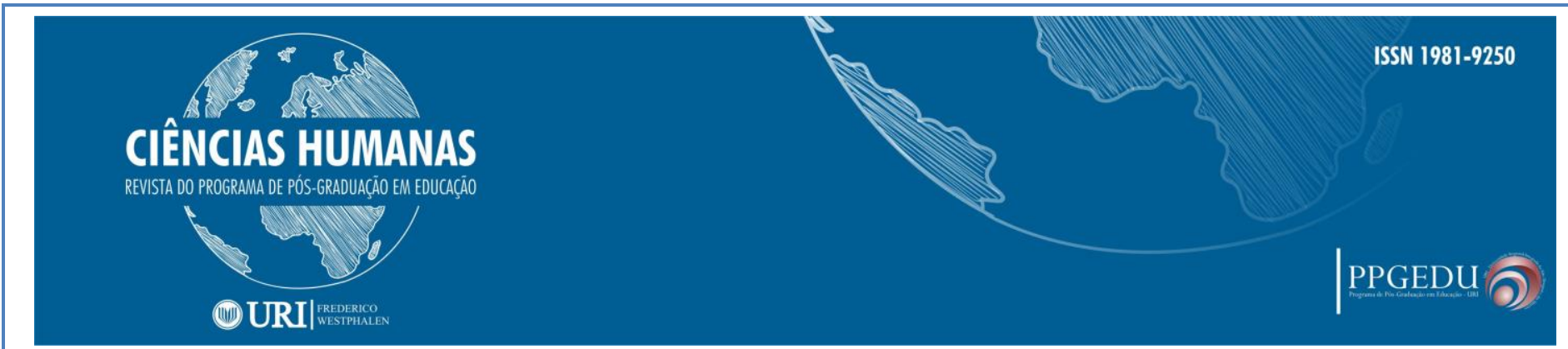

Ao mostrar que a memória é uma construção social, Maurice Halbwachs (1968, traduzido por BENOIR, 2004) apontou que os indivíduos recordam daquilo que consideram importante para seu grupo. Para o autor, as lembranças são sempre coletivas, pois, mesmo que em determinadas circunstâncias se esteja materialmente só, o indivíduo recorda tendo como referenciais estruturas simbólicas e culturais de um grupo social. O pesquisador faz ainda uma clara distinção entre memória histórica e história escrita. A primeira está diretamente relacionada à história vivida, pois esta se baseia em experiências vivenciadas pelo grupo, que busca conservar a imagem do seu passado. Para ele, a história escrita começa onde termina a memória social, pois enquanto esta continuar ativa, não há necessidade de registrá-la por escrito, mas quando ela se distancia no tempo apagando-se na memória dos homens é que entra o historiador relacionando e classificando os fatos "segundo necessidades ou regras que não se impunham ao círculo de homens que por muito tempo foram seu repositório" (HALBWACHS, 2004, p. 100). Por este motivo, há a necessidade de registrar, de forma escrita, as vivências, a cultura dos povos indígenas, pois a partir do momento que estas lembranças se perderem da memória, o registro escrito possibilitará o resgate desta tradição para que ela não se apague.

Literatura de autoria indígena no livro didático para o Ensino Médio: retrato de uma exclusão

Já apontadas as diferentes nomenclaturas de textos literários que tratam a temática indígena e a conceituação de memória social e cultural que sustenta a defesa, neste estudo, da literatura de autoria indígena como um elemento de preservação da memória de nossa nação e do patrimônio imaterial de nossas comunidades ancestrais, passamos à abordagem da presença da literatura indígena em livros didáticos do Ensino Médio. Antes, contudo, fazemos uma pequena contextualização acerca dos objetos analisados.

Escolhemos, como objetos de estudo neste artigo, livros didáticos de Língua Portuguesa que foram ou ainda são destinados ao Ensino Médio de escolas públicas 


\section{CIÊNCIAS HUMANAS}

REVISTA DO PROGRAMA DE PÓS-GRADUAĞ̈O EM EDUCAĞ̄o

\section{(1) URI|}

brasileiras por meio do Programa Nacional do Livro Didático (PNLD), do governo federal brasileiro, que subsidia os materiais didáticos às instituições de ensino básico e que possibilita a substituição dos livros didáticos nas escolas a cada três anos. É importante registrar duas questões sobre o livro didático no Brasil as quais nos serão fundamentais para pensar a presença de textos de indígenas nos livros didáticos. A primeira diz respeito ao fato de esses materiais didáticos fazerem parte do mercado editorial no Brasil e estarem alinhados a interesses de ordem não pedagógica. Célia Cristina de Figueiredo Cassiano (2007), em sua tese de doutorado sobre o Programa Nacional do Livro Didático (PNLD), defende a existência de uma relação entre a política educacional do Brasil e o mercado dos livros didáticos, a qual, segundo ela, é baseada em interesses políticos, comerciais e educacionais. Nesse cenário, a política pública do PNLD tornou o Brasil um dos maiores consumidores de livros didáticos subsidiados pelo Estado, o que impulsionou o interesse de grandes grupos editoriais internacionais na produção desses recursos didáticos para o mercado editorial do país. A segunda refere-se ao fato de que o PNLD não dispõe de livros didáticos específicos para o ensino de literatura brasileira, disciplina que é contemplada, nos livros, coleções didáticas de Língua Portuguesa, mostrando uma inter-relação da língua com a expressão artística verbal e uma atenção aos Parâmetros Curriculares Nacionais para o Ensino Médio que preveem uma integração entre estudos linguísticos e linguagens, já que a literatura é uma das linguagens que devem ser discutidas e ensinadas na sala de aula.

Neste estudo, foram selecionadas as seguintes coleções de livros didáticos de língua portuguesa para o Ensino Médio a serem adotadas nas três séries desse nível de formação: Português: linguagens em conexão, de Graça Sette, Márcia Travalha e Rosário Starling, indicado ao PNLD 2015 a 2017; Português: linguagens, de William Cereja e Thereza Cochar Magalhães, indicado no PNLD 2012 a 2014; Português: ensino médio, de José de Nicola, indicado no PNLD 2009 a 2011. Cada uma dessas coleções tem três volumes, sendo que cada um corresponde a uma série do Ensino Médio. Desses volumes, avaliamos a presença de textos de autoria indígena presentes nos capítulos destinados ao estudo da literatura brasileira. 


\section{CIÊNCIAS HUMANAS}

REVISTA DO PROGRAMA DE PÓS-GRADUAC̄̄o EM EDUCACĞ̄o

\section{(1)URI|}

A coleção de Graça Sette, Márcia Travalha e Rosário Starling, Português: linguagens em conexão, é composta de três partes: literatura e leitura de imagens, gramática e estudo da língua e produção de textos orais e escritos. Na primeira, há a abordagem sobre a literatura, a qual recebe tratamento teórico-crítico que percorre a conceituação do que é texto literário e depois é estimulada ao estudo por meio da periodização literária. Esta engloba tanto a literatura brasileira quanto a portuguesa. Autores canônicos em cada um dos períodos literários são apresentados, inclusive com fragmentos de textos bastante conhecidos na história da literatura brasileira, como Marília de Dirceu, de Tomás Antônio Gonzaga, Memórias póstumas de Brás Cubas, de Machado de Assis, e Morte e vida Severina, de João Cabral de Melo Neto.

Nessa coleção, chama atenção o espaço dado, no terceiro volume, a tendências da literatura brasileira contemporânea, na prosa e na poética, com referência à arte pop e a vozes afro-descendentes e africanas. Mas o grupo social privilegiado é o afrobrasileiro, representado prioritariamente por vozes femininas, com a exclusão de outros escritores que têm representatividade na literatura, como os indígenas. Ou seja, os volumes de Graça Sette, Márcia Travalha e Rosário Starling não fazem alusão a produções orais e escritas de indígenas e nem as reconhecem como pertencentes ao contexto da literatura brasileira contemporânea.

A coleção de William Cereja e Thereza Cochar Magalhães, Português: linguagens, apresenta, em cada um de seus volumes, unidades que associam estudo da língua e da literatura brasileira. Alguns capítulos são voltados exclusivamente para o ensino de literatura brasileira, apresentada segundo a historiografia literária e os períodos literários e, assim, o livro apresenta definições de literatura inicialmente para depois apresentar o Quinhentismo no Brasil, o Barroco, o Arcadismo e assim sucessivamente, dando sequência temporal à apresentação e obras e autores, cujos textos, em sua maioria, aparecem de forma fragmentada no livro. Nesses capítulos específicos sobre literatura, notamos uma tendência em incitar o estudo da literatura por meio da decifração da literatura escrita, já que a literatura oral e seus textos não são mencionados em exercícios ou tópicos sobre a disciplina. 


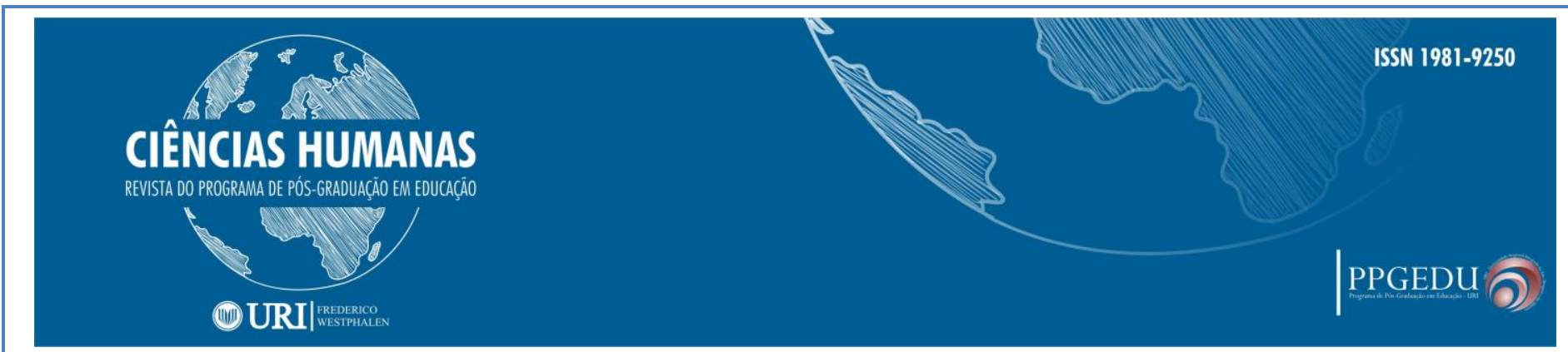

Além disso, há uma variedade de textos e autores apresentados em cada um dos períodos literários, sendo presentes textos de autores canônicos e não canônicos. Contudo, não identificamos, em nenhum dos volumes, textos de autoria indígena que formam a chamada literatura indígena como objetos de apreciação e deleite pelo alunoleitor ou de estudo em sala de aula. Em outras palavras, em nenhum momento, o livro didático, na coleção analisada, propõe o estudo da literatura indígena como componente curricular da literatura brasileira. Isso não significa que não haja alusão a indígenas em textos presentes, parcial ou integramente no livro, já que essa comunidade étnica é referenciada especialmente quando o primeiro volume da coleção aborda a "literatura de informação", no século XVI, no Brasil, e expõe fragmentos de a Carta, de Pero Vaz de Caminha, que é um dos primeiros textos da literatura brasileira que tematizam os nossos povos ancestrais, mesmo que impondo uma visão eurocêntrica e preconceituosa em relação aos primeiros habitantes da terra. Imagens sobre os indígenas também são destacadas no capítulo dedicado ao Arcadismo no Brasil, com a alusão a dois textos clássicos do período: O Uraguai, de Basílio da Gama, e Caramuru, de Santa Rita Durão, e também no capítulo sobre o Romantismo, no qual textos literários brasileiros que apresentam personagens indígenas são comentados, como $O$ guarani, de José de Alencar.

A coleção de José de Nicola, Português: ensino médio, apresenta de forma separada unidades sobre língua portuguesa, literatura e produção textual. Na parte específica sobre literatura, há também unidades destinadas à formação do produtor de textos artísticos, e há uma quantidade significativa de textos e autores da literatura brasileira apesar de serem nomes canônicos em sua grande maioria e representantes de grupos sociais socialmente prestigiados, pertencentes à etnia branca e ao contexto urbano. Assim, avolumam-se textos de autores como Carlos Drummond de Andrade e Guimarães Rosa.

O estudo sobre a literatura nessa coleção de Nicola é também proposto à moda tradicional, uma vez que expõe questões teóricas sobre o conceito de literatura, os gêneros literários e os estilos de época. Depois, didaticamente, contextualiza cada um dos períodos da literatura, equacionando abordagem sobre Portugal e Brasil, e oferece 


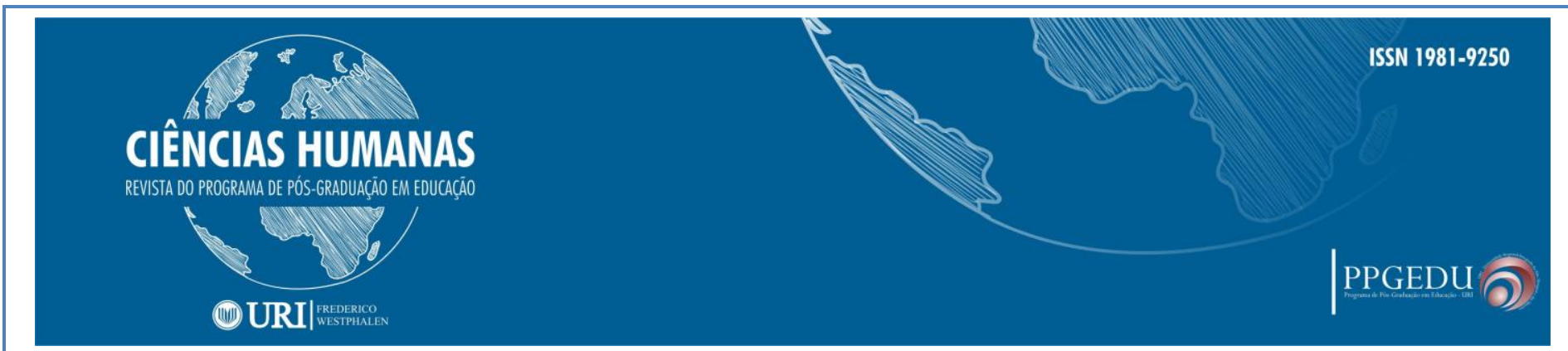

leitura de fragmentos de textos e exercícios para consolidação da aprendizagem, muitos deles com questões objetivas com vistas à preparação para o vestibular. Assim como nas demais coleções, não há espaço algum para a literatura indígena, cujos autores sequer são referenciados no contexto da literatura brasileira contemporânea apesar de seus textos terem recebido atenção em trabalhos acadêmicos de Mestrado e Doutorado no Brasil

A breve descrição sobre as coleções de livros didáticos de língua portuguesa do PNLD para o Ensino Médio aponta a supremacia da literatura escrita no estudo da literatura no Brasil assim como a predominância de autores representativos de períodos literários e leitura de fragmentos de textos literários, o que acena uma a manutenção de uma perspectiva tradicional e conservadora de ensino da disciplina no país. Além disso, apesar de haver lei federal que obriga a abordagem Relações Étnico-Raciais e bem como do Ensino de História e Cultura Afro-Brasileira, Africana e Indígena nas salas de aula brasileiras, o que vemos é uma desatenção a essa determinação nos livros didáticos examinados, o que, em tese, sinaliza uma dissonância entre a legislação educacional e meios didáticos financiados pelo próprio Estado para a execução de projetos de formação no Ensino Médio.

Para ilustrar a presença, ou melhor ausência, da literatura de autoria indígena em livros didáticos do PNLD, apresentamos o quadro a seguir, que sintetiza as observações quanto ao que descrevemos nos parágrafos anteriores e mostra claramente o retrato de apagamento da literatura indígena em livros didáticos do PNLD:

QUADRO 1 - Síntese quantitativa de textos da literatura de autoria indígena nas coleções analisadas

\begin{tabular}{|l|c|l|c|}
\hline Item analisado & $\begin{array}{l}\text { Português: linguagens } \\
\text { em conexão }\end{array}$ & $\begin{array}{l}\text { Português: } \\
\text { linguagens }\end{array}$ & $\begin{array}{l}\text { Português: ensino } \\
\text { médio }\end{array}$ \\
\hline $\begin{array}{l}\text { Quantidade de textos de } \\
\text { autoria indígena }\end{array}$ & 0 & 0 & 0 \\
\hline
\end{tabular}

Fonte: Autoras

Como podemos perceber, temos um retrato da exclusão da literatura indígena nos bancos escolares nos quais as coleções didáticas são adotadas como instrumento 


\section{CIÊNCIAS HUMANAS}

REVISTA DO PROGRAMA DE PÓS-GRADUAĞ̈O EM EDUCAĞ̄o

\section{(10)URI|}

pedagógico. Se o estudo da literatura brasileira for seguido com o apagamento das vozes indígenas e de suas produções literárias, tal como sugerem os livros didáticos analisados, teremos uma construção de memória social e cultural falha, lacunar e discriminatória por permitir a preponderância de grupos de escritores pertencentes a comunidade não indígena e por incitar a ideia de que a literatura brasileira se faz com autores brancos ou afro-brasileiros apenas.

Ademais, se o conceito de memória social é ético e político e um ato de construção processual, como propõe Condar (2005), podemos supor que, a exemplo da história da literatura brasileira contada por meio dos livros didáticos analisados, o saber sobre a matéria "literatura brasileira" registrado por meio da "história literária contada" nos livros é um saber pautado em leituras individualizadas que são apresentadas como percepções coletivas, quando, na verdade, ao contrário, são leituras que promovem a segregação e o apagamento de vozes, autores e textos que fazem parte do arcabouço literário brasileiro. O retrato da exclusão da literatura indígena que apresentamos, mesmo que não possa ser generalizado em função da quantidade de coleções analisadas, aponta que a memória sobre a literatura brasileira exposta nos livros didáticos examinados não é um sinônimo de representação coletiva apesar de ser coletivo a socialização dessa memória, tendo em vista o número de estudantes-leitores que usufruem dos materiais como aporte de ensino.

Se nos detivermos na percepção de Maurice Halbwachs (1968), para quem a memória é uma construção social elaborada com base em recordações de determinados grupos que consideram determinados textos como importantes de serem registrados, ainda poderemos conjecturar que as lembranças coletivas de textos e literatura registrados nos livros didáticos são referenciais simbólicos e culturais de um grupo social que escreve a história de acordo com seus valores e visões de mundo e na qual grupos minoritários, como o dos indígenas, não são considerados relevantes para serem lembrados ou terem sua literatura conhecida, aprendida, cultuada. Seria isso uma nova forma de aculturação traduzida em um repertório de leituras a ser reproduzido na escola e que está a serviço de uma ideologia de colonização do pensamento e da memória social e história de nossas letras? Mesmo que não tenhamos dados suficientes para 


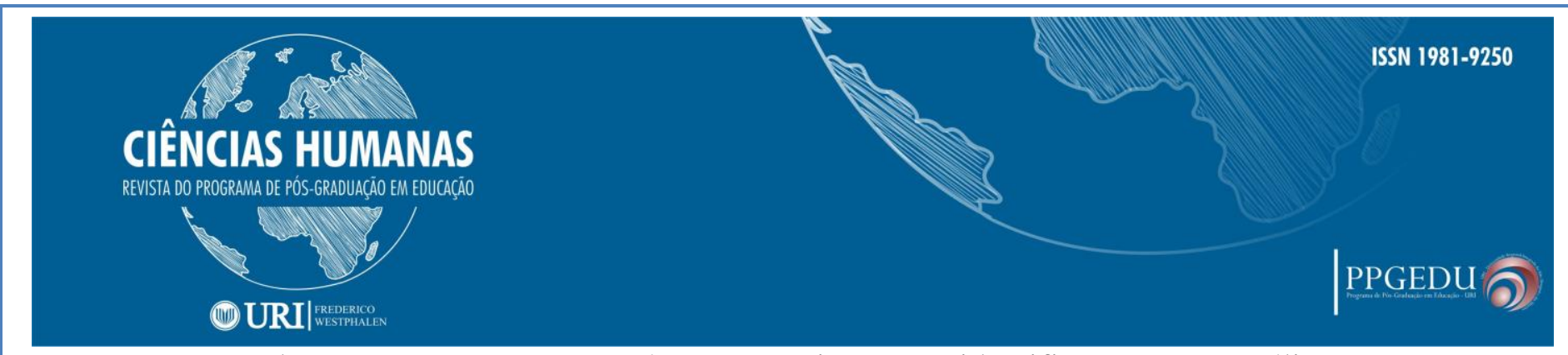

responder essa questão, os números vazios que identificamos na análise que construímos nos leva a pensar que sim. E esse sim vem acompanhado de outros apontamentos que merecem ser registrados, como o fazemos nas considerações da seção seguinte deste texto.

\section{CONSIDERAÇÕES FINAIS}

O exame das três coleções de língua portuguesa para o Ensino Médio disponibilizadas pelo PNLD nestes últimos oito anos sinaliza haver, nessas obras didáticas, uma predominância de vozes de origem eurocêntrica na autoria de textos literários apresentados aos estudantes de literatura brasileira no ensino médio, o que parecer ser um contraste com a formação étnica brasileira, marcada pela pluralidade e presença de nossos aborígenes. Mesmo que fatores históricos e sociais justifiquem a supremacia de determinados grupos étnicos no Brasil sobre outros, não seria plausível reproduzir desigualdade étnica no ensino brasileiro por meio do apagamento de produções literárias de grupos social e economicamente fragilizados no cenário contemporâneo do país.

Nesse contexto, podemos ainda discutir a ausência da literatura de autoria indígena no livro didático para o Ensino Médio como reflexo de uma violência simbólica praticada no país contra os povos indígenas ao longo do processo histórico desde a colonização até os dias atuais. A dizimação dos povos indígenas ocorrida ao longo dos últimos quinhentos anos encontra continuidade no apagamento dos textos de indígenas na história da literatura contada nos livros didáticos como os analisados. Se a história social brasileira é marcada por violência contra indígenas, a história da literatura também o é.

Tal observação pode ser ampliada na medida em que esse apagamento da literatura de autoria indígena no livro didático ratifica ou incita a ideia de que a literatura brasileira é composta apenas de textos escritos e de autores pertencentes a grupos sociais mais prestigiados no cenário da crítica literária dominante, percepção que 


\section{CIÊNCIAS HUMANAS}

REVISTA DO PROGRAMA DE PÓS-GRADUAĞ̈O EM EDUCAĞ̄o

\section{(1) URI|}

desconsidera como válidas produções que não atendem a critérios de gosto daqueles que formam e modulam as escolhas de textos a serem lidos e ensinados nas escolas.

Por fim, mas não menos importante, cabe ressaltar que os livros didáticos analisados, pela forma como indicam os caminhos para um ensino de literatura no Ensino Médio, mostram-se em posição contrária a teorias e tendências atuais sobre ensino de literatura, as quais preveem a pluralidade de vozes e autorias, assim como de temas e formas literárias. E o que é mais sério, o apagamento da literatura de autoria indígena no livro didático ofertado pelo governo federal através do PNLD a escolas públicas pode ser visto, no plano discursivo e pragmático, como forma de legitimação estatal do valor de inferioridade atribuído historicamente à comunidade indígena e à sua literatura.

\section{REFERÊNCIAS}

BONIN, Iara Tatiana. Representações da criança na literatura de autoria indígena Estudos de literatura brasileira contemporânea, n. 46, p. 21-47, jul./dez, 2015.

CASSIANO, Célia C. de Figueiredo. O mercado do livro didático no Brasil: da criação do Programa Nacional do Livro Didático (PNLD) à entrada do capital internacional espanhol (1985-2007).Tese (Doutorado) área de concentração: Educação, Pontifícia Universidade Católica, SP: (252 p.), 2007. Disponível em: $<$ http://www.sapientia.pucsp.br/tde_busca/arquivo.php?codArquivo=5304>. Acesso em: 02 abr. 2015.

GRAÚNA, Graça. Contrapontos da literatura indígena contemporânea no Brasil. Belo Horizonte: Mazza Edições, 2013.

GUESSE, Érika Bergamasco. Da oralidade à escrita: os mitos e a literatura indígena no Brasil. Anais do SILEL. Volume 2, Número 2. Uberlândia: EDUFU, 2011.

MUNDURUKU, Daniel. O Banquete dos Deuses: conversa sobre a origem da cultura brasileira. 2. ed. São Paulo: Global, 2009.

\section{SOUZA, Lynn Mario T. Menezes de. Uma outra história, a escrita indígena no}

Brasil. 2006. Disponível em: <http://pib.socioambiental.org/pt/c/iniciativasindigenas/autoriaindigena/uma-outra-historia,-a-escrita-indigena-no-brasil > . Acesso em: 8 nov. 2016. 


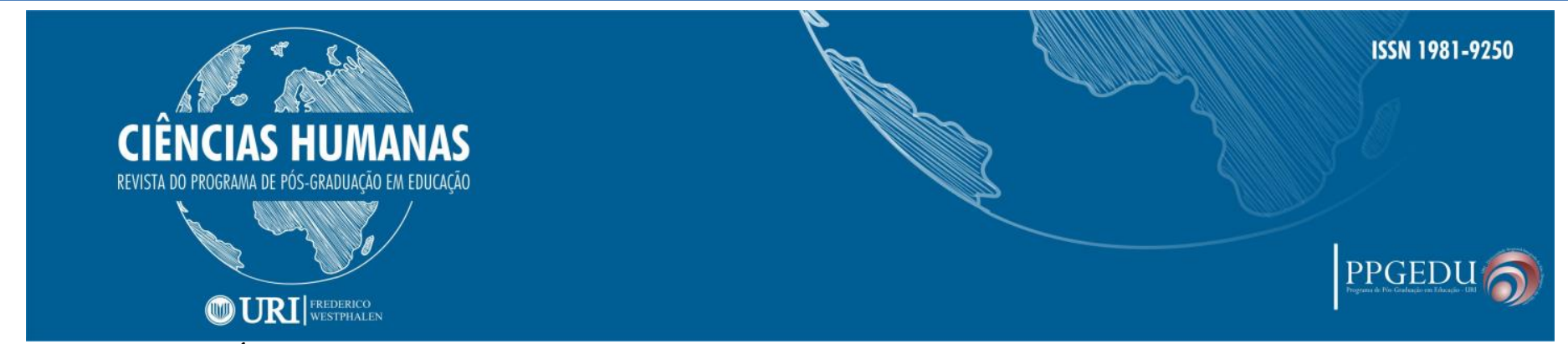

THIÉL, Janice Cristine. Pele silenciosa, pele sonora: a construção da identidade indígena brasileira e norte-americana na literatura. Tese. (Doutorado). Área de concentração: Estudos Literários, Universidade Federal do Paraná, PR: (376 p.), 2006. Disponível em:

$<$ https://acervodigital.ufpr.br/bitstream/handle/1884/19188/Tese? sequence=1>. Acesso em: 02 abr. 2017. 